\title{
FREQUENCY OF RIGHT VENTRICULAR INFARCTION AND IN-HOSPITAL OUTCOME AFTER PRIMARY PERCUTANEOUS CORONARY INTERVENTION (PPCI) IN ACUTE INFERIOR MYOCARDIAL INFARCTION (MI)
}

\author{
Mohsin Saif, Shoaib Iqbal Safi, Ariz Samin, Fahd-ur-Rahman, Jasia Bukhari, Sajid Khan \\ Armed Forces Institute of Cardiology/National Institute of Heart Disease (AFIC/NIHD)/National University of Medical Sciences (NUMS) \\ Rawalpindi Pakistan
}

\begin{abstract}
Objective: To determine the frequency of Right Ventricle infarction and in-hospital outcome after primary percutaneous coronary intervention in patients with acute inferior MI.

Study Design: Descriptive Cross Sectional Study.

Place and Duration of Study: Armed Forces Institute of Cardiology/National Institute of Heart Diseases, from Dec 2018 to Jun, 2019.

Methodology: Non-probability consecutive sampling technique was used. Permission was sought from hospital ethical committee and informed consent was taken from participants of the study. Patients presenting with acute inferior MI who underwent Primary Percutaneous Coronary Intervention were assessed for presence of Right Ventricle infarct. All the patients' data and variables of the study was recorded in the data collection sheet. Patients underwent venous blood sampling for Complete blood count, Renal function tests, Liver function tests, Blood glucose random, Troponin-I, cardiac enzymes and Coagulation profile at presentation in emergency department.

Results: Total 261 patients were included according to the inclusion criteria of the study. Mean age (years) in the study was $58.0 \pm 12.59$ whereas there were 183 (70.1) male and 78 (29.9) female patients who were included in the study. Frequency of right ventricular infarction and in-hospital outcome (mortality) after Primary Percutaneous Coronary Intervention in patients with acute inferior MI was assessed in the study which was 73 (28.0) and 20 (7.7) respectively.

Conclusion: The study concluded that frequency of in-hospital mortality is substantial due to major adverse cardiac events in patients with right ventricle infarction.
\end{abstract}

Keywords: Acute Myocardial Infarction, Right Ventricular Infarction, ST Elevation.

This is an Open Access article distributed under the terms of the Creative Commons Attribution License (http://creativecommons.org/licenses/by/4.0), which permits unrestricted use, distribution, and reproduction in any medium, provided the original work is properly cited.

\section{INTRODUCTION}

Myocardial infarction is a segmental disease of myocardium with a focal occlusion of one of three large coronary arteries (CA) or its branches during any particular event resulting in impairment of contractility restricted to the affected segment $\mathrm{t}^{1,2}$. Major cause of myocardial infarction (Ml) is atherosclerotic coronary artery disease (CAD). It contributes to arterial stenosis, increased tendency for rupture of plaque and development of clot. Until recently, Ml was considered a disease of left ventricle (LV) only. Right ventricular infarctions (RVIs) are frequently associated with extensive inferior-posterior myocardial infarctions.

Correspondence: Dr Mohsin Saif, Consultant Cardiologist, AFIC/NIHD Rawalpindi Pakistan
The diagnosis of RVI should always be considered in patients who have an inferior wall myocardial infarction. The signs and symptoms of RVI are similar to those of left ventricular infarction. Clinically, the triad of hypotension, elevated jugular venous pressure (JVP), and clear lung fields is recognized as a marker of RVI in patients with acute infero-posterior wall infarction ${ }^{3,4}$. The presence of acute ST segment elevation in the right precordial leads (V3R to V6R), is highly reliable in the diagnosis of RVI. ST segment elevation $>0.1 \mathrm{mV}$ in the right precordial leads, especially V4R, is observed in $60-90 \%$ of patients with acute $\mathrm{RVMI}^{5}$. It correlates with reduced right ventricle (RV) ejection fraction and is strongly associated with major complications and in-hospital mortality ${ }^{6,7}$. Early recognition of RVI is critical for redu- 
cing mortality and complications associated with this cardiac injury. Inferior myocardial infarction with RVI has a high mortality rate of $25 \%$ to $30 \%$ as compared with only $6 \%$ for inferior infarctions not involving the right ventricle. Dysrhythmias such as bradycardia, high-degree atrioventricular block, and atrial fibrillation are associated with approximately 50\% of RV Infarctions7. Lempereur et al confirmed the presence of female predominance in developing RV infarction ${ }^{8}$. Goldstein et al has predicted in-hospital mortality of 14 percent in patients presenting with RV infarct 9. Early detection, along with hemodynamic support, rapid reperfusion therapy, and knowledge of the potential complications, can help improve the outcome of patients with RVI. RV involvement portends a worse prognosis to uncomplicated inferior MI, with hemodynamic and electrophysiological complications increasing inhospital morbidity and mortality. Very few local studies were conducted so far. A study conducted at National Institute of Cardiovascular Diseases Karachi reported 34\% prevalence of RVMI ${ }^{10}$. This study aims at documenting the frequency and outcomes in terms of major adverse cardiac events (MACE) and associated risk factors, which play a significant role on the adverse cardiovascular events associated with RV infarct.

\section{METHODOLOGY}

This descriptive cross sectional study was carried out at Armed Forces Institute of Cardiology/National Institute of Heart Diseases from 27th Dec, 2018 to 27th Jun, 2019. A Non-probability consecutive sampling technique was used. Hospital ethical committee approved the study and all participants gave their informed written consent. All the patients presenting with acute inferior MI who underwent Primary Percutaneous Coronary Intervention (PPCI) were considered for the study. Reseachers assessed for presence of Right Ventricle (RV) infarct which was defined as ST segment elevation of $>1 \mathrm{~mm}$ in chest lead V4R, along with hypotension and a systolic blood pressure of $<90 \mathrm{mmHg}$ at presentation. Outcome was measured as occurrence of MACE (Major Adverse Cardiovascular Events) i.e. non-fatal MI, stroke and death occurring within 72 hours of hospital admission or prior to discharge. Patients with previous history of MI, PCI, Coronary Artery Bypass Grafting (CBAG), thrombolysis and not willing for PPCI were excluded from the study. All the patients' data and variables of the study were recorded in the data collection sheet. Patients underwent venous blood sampling for Complete blood count (CBC), Renal function tests (RFT's), Liver function tests (LFT's), Blood glucose random (BSR), Troponin-I, cardiac enzymes and Coagulation profile at presentation in emergency department. Fasting Lipid profile was collected within 24 hours of admission. Troponin-I was collected 6 hour post PPCI and at the time of recurrent symptoms or ECG findings consistent with recurrent MI. After PPCI, patient stayed for at least 24 hours in a monitored post-catheterization ward. Patients were followed up for in-hospital MACE. Inhospital MI was defined by elevation of cardiac troponin values $>5$ times the upper reference limit in patients with normal baseline values or a rise of cardiac troponin values $>20 \%$ if the baseline values were elevated. Stroke was defined as an acute episode of focal or global neurological dysfunction caused by brain, spinal cord, or retinal vascular injury as a result of hemorrhage or infarction which was confirmed by computerized tomography (CT) scan of Brain. All genders aged between 30 and 75 with first MI who underwent PPCI were included in the study keeping in consideration the culprit vessel and all the comorbid conditions. Statistical analysis was performed using statistical software SPSS23. Mean and standard deviation was calculated for quantitative variable i.e. age, Troponin-I. Frequency and percentage was calculated for qualitative variable i.e. gender, MACE (death, stroke, nonfatal MI), diabetes, dyslipidemia, hypertension, RV infarct, vesselinvolvement. Post stratification chi-square test was applied. A $p$-value less than 0.05 was significant.

\section{RESULTS}

Total 261 patients were included according to the inclusion criteria of the study. There were 
$183(70.1 \%)$ male and 78 (29.9\%) female patients. Meanage in the study was $58.0 \pm 12.59$ years with

Table-I: Frequency of RV infarct after PPCI in patients With acute inferior MI.

\begin{tabular}{l|c|c}
\hline & Frequency & Percentage \\
\hline Yes & 73 & 28.0 \\
\hline No & 188 & 72.0 \\
\hline Total & 261 & 100.0 \\
\hline
\end{tabular}

Table-II: Frequency of in-hospital outcome after PPCI in patients with acute inferior MI.

\begin{tabular}{l|c|c}
\hline & Frequency & Percentage \\
\hline Non-fatal MI & 8 & 3.1 \\
\hline Death & 20 & 7.7 \\
\hline Stroke & 10 & 3.8 \\
\hline Nil & 223 & 85.4 \\
\hline Total & 261 & 100.0 \\
\hline
\end{tabular}

a range from 30 to 75 years. Mean troponin-I levels of patients were $0.41 \pm 0.16$. Fifty two (19.9\%) patients had Diabetes Mellitus (DM), dyslipidemia was present in 54 (20.7\%) and associated with the presence of RV infarction but none of this association was statistically significant ( $p$-value $<0.05)$ as shown in table-III. Out of total study population, $8(3.1 \%)$ patients suffered non-fatal MI, $10(3.8 \%)$ had stroke and $20(7.7 \%)$ died (table-II). Age more than 50 years, male gender, on-diabetic non-hypertensive patients with no lipid disorders, RCA (Right Coronary Artery) involvement, raised cardiac bio markers and absence of LV (Left Ventricle) dysfunction were associated with associated with MACE (Major Adverse Cardiovascular Events) including nonfatal MI, stroke and death as shown in table-IV. This association in non-diabetic group was statistically significant ( $p$-value 0.049).

\section{DISCUSSION}

Acute myocardial infarction is defined as a clinical event caused by myocardial ischemia in which there is evidence of myocardial injury or

Table-III: Clinical characteristics and their association with RV infarction.

\begin{tabular}{|c|c|c|c|c|c|}
\hline \multicolumn{2}{|l|}{ Clinical Characteristics } & \multicolumn{3}{|c|}{ Right Ventricle(RV) Infarct } & \multirow[t]{2}{*}{$p$-value } \\
\hline & & Present & Absent & Total & \\
\hline Age Group & $\begin{array}{l}<50 \\
>50\end{array}$ & $\begin{array}{l}16(21.9 \%) \\
57(78.1 \%)\end{array}$ & $\begin{array}{c}38(20.2 \%) \\
150(79.8 \%)\end{array}$ & $\begin{array}{c}54(20.7 \%) \\
207(79.3 \%)\end{array}$ & 0.760 \\
\hline Gender & $\begin{array}{c}\text { Male } \\
\text { Female }\end{array}$ & $\begin{array}{l}49(67.1 \%) \\
24(32.9 \%)\end{array}$ & $\begin{array}{c}134(71.3 \%) \\
54(28.7 \%)\end{array}$ & $\begin{array}{c}183(70.1 \%) \\
78(29.9 \%)\end{array}$ & 0.511 \\
\hline Diabetes Mellitus (DM) & $\begin{array}{l}\text { Yes } \\
\text { No }\end{array}$ & $\begin{array}{l}13(17.8 \%) \\
60(82.2 \%)\end{array}$ & $\begin{array}{c}39(20.7 \%) \\
149(79.3 \%)\end{array}$ & $\begin{array}{c}52(19.9 \%) \\
209(80.1 \%)\end{array}$ & 0.594 \\
\hline Dyslipidemia & $\begin{array}{l}\text { Yes } \\
\text { No }\end{array}$ & $\begin{array}{l}13(17.8 \%) \\
60(82.2 \%)\end{array}$ & $\begin{array}{c}41(21.8 \%) \\
147(78.2 \%)\end{array}$ & $\begin{array}{c}54(20.7 \%) \\
207(79.3 \%)\end{array}$ & 0.474 \\
\hline Hypertension & $\begin{array}{l}\text { Yes } \\
\text { No }\end{array}$ & $\begin{array}{l}27(37.0 \%) \\
46(63.0 \%)\end{array}$ & $\begin{array}{c}61(32.4 \%) \\
127(67.9 \%)\end{array}$ & $\begin{array}{c}88(33.7 \%) \\
173(66.3 \%)\end{array}$ & 0.486 \\
\hline Coronary Artery Involved & $\begin{array}{l}\text { RCA } \\
\text { LCx }\end{array}$ & $\begin{array}{l}56(76.7 \%) \\
17(23.3 \%)\end{array}$ & $\begin{array}{c}153(81.4 \%) \\
35(18.6 \%)\end{array}$ & $\begin{array}{l}70(26.8 \%) \\
52(19.9 \%)\end{array}$ & 0.396 \\
\hline Troponins & $\begin{array}{c}\text { Normal } \\
\text { Raised }\end{array}$ & $\begin{array}{c}3(4.1 \%) \\
70(95.9 \%)\end{array}$ & $\begin{array}{c}12(6.4 \%) \\
176(93.6 \%)\end{array}$ & $\begin{array}{c}15(5.7 \%) \\
246(94.3 \%)\end{array}$ & 0.479 \\
\hline LV Dysfunction & $\begin{array}{l}\text { Yes } \\
\text { No }\end{array}$ & $\begin{array}{l}16(21.9 \%) \\
57(78.1 \%)\end{array}$ & $\begin{array}{c}54(28.7 \%) \\
134(71.3 \%)\end{array}$ & $\begin{array}{c}70(26.8 \%) \\
191(73.2 \%)\end{array}$ & 0.265 \\
\hline
\end{tabular}

hypertension in $88(33.7 \%)$. Frequency of right ventricular (RV) infarction after PPCI in patients with acute inferior MI was $n=73(28 \%)$, as shown in table-I. Age more than 50 years, male gender, on-diabetic and non-hypertensive patients with no lipid disorders, RCA (Right Coronary Artery) involvement, raised cardiac bio markers and absence of LV (Left Ventricle) dysfunction were necrosis ${ }^{11}$. The World Health Organization estimated in 2004 , that $12.2 \%$ of worldwide deaths were from ischemic heart disease; with it being the leading cause of death in high- or middleincome countries and second only to lower respiratory infections in lower-income countries. Worldwide, more than 3 million people have STEMIs and 4 million have NSTEMIs a year ${ }^{12}$. In 
Pakistan the prevalence of acute coronary syndrome is increasing rapidly due to increasing prevalence of risk factors of atherosclerosis, which is the major cause of acute coronary syndrome ${ }^{10}$. In Pakistan coronary artery disease causes more than 100,000 deaths ( $12 \%$ of total deaths) annually ${ }^{13,14}$. The most common symptom is chest pain or discomfort that may travel into the least one value above the 99th percentile of the upper reference limit, together with evidence of myocardial ischemia. In our study, Mean age (years) in the study was $58.0 \pm 12.59$. Similarly, in a study conducted by Khan et al 10 mean age in years was $56.3 \pm 13.1^{10}$. In our study, there were 183 (70.1) male and 78 (29.9) female patients. Likewise, in a study conducted by Sawar et al

Table-IV: Clinical Characteristics And Their Association With In-Hospital Mortality.

\begin{tabular}{|c|c|c|c|c|c|}
\hline \multicolumn{2}{|l|}{ Clinical Characteristics } & \multicolumn{3}{|c|}{ In-Hospital Outcome } & \multirow[t]{2}{*}{$p$-value } \\
\hline \multirow{3}{*}{ Age Group } & & Non-fatal MI & Stroke & Death & \\
\hline & $<50$ & $1(12.5 \%)$ & $3(30.0 \%)$ & $5(25.0 \%)$ & \multirow{2}{*}{0.773} \\
\hline & $>50$ & $7(87.5 \%)$ & $7(70.0 \%)$ & $15(75.0 \%)$ & \\
\hline \multirow{2}{*}{ Gender } & Male & $5(62.5 \%)$ & $5(50.0 \%)$ & $13(65.0 \%)$ & \multirow{2}{*}{0.443} \\
\hline & Female & $3(37.5 \%)$ & $5(50.0 \%)$ & $7(35.0 \%)$ & \\
\hline \multirow{2}{*}{ Diabetes Mellitus (DM) } & Yes & $3(37.5 \%)$ & $5(50.0 \%)$ & $3(15.0 \%)$ & \multirow{2}{*}{0.049} \\
\hline & No & $5(62.5 \%)$ & $5(50.0 \%)$ & $17(85.0 \%)$ & \\
\hline \multirow{2}{*}{ Dyslipidemia } & Yes & $2(25.0 \%)$ & $3(30.0 \%)$ & $4(20.0 \%)$ & \multirow{2}{*}{0.883} \\
\hline & No & $6(75.0 \%)$ & $7(70.0 \%)$ & $16(80.0 \%)$ & \\
\hline \multirow{2}{*}{ Hypertension } & Yes & $4(50.0 \%)$ & $5(50.0 \%)$ & $6(30.0 \%)$ & \multirow{2}{*}{0.502} \\
\hline & No & $4(50.0 \%)$ & $5(50.0 \%)$ & $14(70.0 \%)$ & \\
\hline \multirow{2}{*}{ Coronary Artery Involved } & RCA & $6(75.0 \%)$ & $10(100.0 \%)$ & $16(80.0 \%)$ & \multirow{2}{*}{0.442} \\
\hline & LCx & $2(25.0 \%)$ & - & $4(20.0 \%)$ & \\
\hline \multirow{2}{*}{ Troponins } & Normal & $1(12.5 \%)$ & $2(10.0 \%)$ & - & \multirow{2}{*}{0.571} \\
\hline & Raised & $7(87.5 \%$ & $18(90 \%)$ & $10(100.0 \%)$ & \\
\hline \multirow{2}{*}{ LV Dysfunction } & Yes & $1(12.5 \%)$ & $4(40.0 \%)$ & $4(20.0 \%)$ & \multirow{2}{*}{0.527} \\
\hline & No & $7(87.5 \%)$ & $6(60.0 \%)$ & $16(80.0 \%)$ & \\
\hline
\end{tabular}

shoulder, arm, back, neck or jaw. Often it is in the center or left side of the chest and lasts for more than a few minutes ${ }^{15,16}$. The discomfort may occasionally feel like heartburn. Other symptoms may include shortness of breath, nausea, feeling faint, a cold sweat or feeling tired. About $30 \%$ of people have atypical symptoms, with women more likely than men to present atypically. Among those over 75 years old, about $5 \%$ have had an MI with little or no history of symptoms 17,18 . Non-modifiable risk factors for atherosclerosis include increasing age, male, family history of premature $\mathrm{CHD}$, premature menopause and modifiable risk factors for atherosclerosis include smoking, diabetes mellitus (and impaired glucose tolerance), metabolic syndrome, hypertension, hyperlipidemia, obesity and physical inactivity. The new criteria for diagnosing myocardial infarction are detection of rise and/or fall of cardiac biomarkers (preferably troponin) with at frequency and percentage of male and female patients were 36 (60) and 34 (57) respectively. A study conducted in 2016, observed that the frequency and percentage of diabetes and hypertension among patients were found to be 22 (37) and 28 (47) respectively. Likewise, in our study, there were 52 (19.9) patients of diabetes presented in the study and hypertension in 88 (33.7) patients. In our study, frequency of right ventricular (RV) infarction after PPCI in patients with acute inferior MI was assessed, which was $28.0 \%$. Consequently, in a study conducted by Sawar et al anticipated incidence of RV infarction was $21.6 \%$ with inferior MI using criteria of $\geq 1 \mathrm{~mm}$ ST segment elevation in V4R. A study by Goldstein et al has predicted in-hospital mortality of $14 \%$ in patients presenting with RV infarct ${ }^{9}$. Similarly in our study, out of 261 cases, there were $7.7 \%$ cases of mortality documented. 


\section{CONCLUSION}

The study concluded that there is substantial in-hospital mortality due to Major Adverse Cardiac Events (MACE) in patients presenting with acute inferior MI complicated with RV infarction.

\section{CONFLICT OF INTEREST}

This study has no conflict of interest to be declared by any author.

\section{REFERENCES}

1. Kinch JW, Ryan TJ. Right ventricular infarction. N Engl J Med 1994; 330(17): 1211-17.

2. Albulushi A, Giannopoulos A, Kafkas N, Dragasis S, Pavlides G, Chatzizisis YS. Acute right ventricular myocardial infarction. Expert Rev Cardiovascular Ther 2018; 16(1): 455-64.

3. Goldstein JA. Acute right ventricular infarction: insights for the interventional era. Curr Probl Cardiol 2012; 37(12): 533-57.

4. Inohara $\mathrm{T}$, Kohsaka S, Fukuda K, Menon V. The challenges in the management of right ventricular infarction. Eur Hear J Acute Cardiovasc Care 2013; 2(3): 226-34.

5. Fijewski TR, Pollack ML, Chan TC, Brady WJ. Electrocardiographic manifestations: Right ventricular infarction. J Emerg Med 2002; 22(2): 189-94.

6. Miszalski-Jamka T, Klimeczek P, Tomala M, Krupiński M, Zawadowski G, Noelting J, et al. Extent of RV dysfunction and myocardial infarction assessed by CMR are independent outcome predictors early after STEMI treated with primary angioplasty. JACC Cardiovasc Imag 2010; 3(12): 1237-46.

7. Van Der Zwaag PA, Van Rijsingen IAW, Asimaki A, Jongbloed JDH, Van Veldhuisen DJWA, et al. Phospholamban R14del mutation in patients diagnosed with dilated cardiomyopathy or arrhythmogenic right ventricular cardiomyopathy: Evidence supporting the concept of arrhythmogenic cardiomyopathy. Eur
J Heart Fail 2012; 8(0): 2011-13.

8. Lempereur M, Magne J, Cornelis K, Hanet C, Taeymans Y, Vrolix M, et al. Impact of gender difference in hospital outcomes following percutaneous coronary intervention. Results of the Belgian Working Group on Interventional Cardiology (BWGIC) registry. Euro Intervent 2016; 12(2): e216-23.

9. Goldstein JA, Kommuri N, Dixon SR. Left ventricular systolic dysfunction is associated with adverse outcomes in acute right ventricular infarction. Coron Artery Dis 2016; 27(4): 277-86.

10. Khan S, Kundi A, Sharieff S. Prevalence of right ventricular myocardial infarction in patients with acute inferior wall myocardial infarction. Int J Clin Pract 2004; 58(4): 354-57.

11. Gulati R, Behfar A, Narula J, Kanwar A, Lerman A, Cooper L, et al. Acute Myocardial Infarction in Young Individuals. Mayo Clin Proceed 2020; 95(1): 136-56.

12. Sulo G, Igland J, Vollset SE, Ebbing M, Egeland GM, Ariansen I, et al. Trends in incident acute myocardial infarction in Norway: An updated analysis to 2014 using national data from the CVDNOR project. Eur J Prev Cardiol 2018; 25(10): 1031-39.

13. Jafar TH. Women in Pakistan have a greater burden of clinical cardiovascular risk factors than men. Int J Cardiol 2006; 106(3): 348-54.

14. Risk Factors of Cardiovascular Disease and Its Recommendations in Pakistani Context - PubMed Available from: https:// pubmed.ncbi.nlm.nih.gov/29171568/

15. Ng R, Yeghiazarians Y. Post myocardial infarction cardiogenic shock: A review of current therapies. J Intensive Care Med 2013; 28(1): 151-65.

16. Bajaj A, Sethi A, Rathor P, Suppogu N, Sethi A. Acute Complications of Myocardial Infarction in the Current Era: Diagnosis and Management. J Investigative Med 2015; 63(7): 844-55.

17. Edwards M, Chang AM, Matsuura AC, Green M, Robey JM, Hollander JE. Relationship between pain severity and outcomes in patients presenting with potential acute coronary syndromes. Ann Emerg Med 2011; 58(6): 501-07.

18. Arora G, Bittner V. Chest Pain Characteristics and Gender in the Early Diagnosis of Acute Myocardial Infarction. Curr Cardiol Rep 2015; 17(1): 1-5. 